\title{
PREPARATION AND IN VITRO EVALUATION OF CYCLODEXTRIN BASED EFFERVESCENT AND DISPERSIBLE GRANULES OF CARBAMAZEPINE
}

\section{HUSSAIN ALI M. HUSSAIN¹, EMAN B. H. AL-KHEDAIRY2*}

\author{
1Ministry of Health and Environment, Baghdad, Iraq, 2Department of Pharmaceutics, College of Pharmacy/University of Baghdad, \\ Baghdad, Iraq \\ Email: emanalkhedairy@yahoo.com
}

Received: 03 Jul 2018, Revised and Accepted: 15 Oct 2018

\section{ABSTRACT}

Objective: Carbamazepine is typically used for the treatment of seizure disorders and neuropathic pain. One of the major problems with this drug is its low solubility in water; therefore the objective of this study was to enhance the solubility of carbamazepine by complexation with cyclodextrin to be formulated as effervescent and dispersible granules.

Methods: Solvent evaporation method was used to prepare, binary (Carbamazepine/ $\beta$-cyclodextrin) complex and ternary (Carbamazepine/ $\beta$ cyclodextrin/hydroxypropyl methyl cellulose (HPMC E5). The more soluble complex will be further formulated as unit dose effervescent and dispersible granules. The complexes were evaluated for their solubility, drug content, percentage practical yield and differential scanning calorimetery (DSC) to confirm the formation of the complex.

Results: The ratio of effervescent components, amount of effervescent base, amount of croscarmellose sodium (superdisintegrant) within the formula were found to play a role in the percentage of drug dissolved. Among the all prepared formulas, the effervescent granules containing ternary complex equivalent to 200 or 100 carbamazepine with effervescent base of 1:2:3.4 citric acid: tartaric acid: sodium bicarbonate not less than $48 \% \mathrm{w} / \mathrm{w}$ and $3 \% \mathrm{w} / \mathrm{w}$ croscarmellose sodium within the formula may be considered as a promising formulas regarding the amount of drug dissolved within 5 min.

Conclusion: The solubility of carbamazepine was enhanced by complexation with $\beta$-cyclodextrin and HPMC E5 as a ternary complex. Hence effervescent and dispersible granules of carbamazepine with good flow properties can be successfully prepared by using this complex.

Keywords: Carbamazepine, $\beta$-cyclodextrin, HPMCE5, Effervescent granules, Effervescent base

(C) 2018 The Authors. Published by Innovare Academic Sciences Pvt Ltd. This is an open access article under the CC BY license (http://creativecommons.org/licenses/by/4.0/) DOI: http://dx.doi.org/10.22159/ijap.2018v10i6.28276

\section{INTRODUCTION}

Granules including effervescent granules are popular delivery systems for many pharmaceutical products. They provide a highly palatable formula which can avoid bitter taste of drugs with ease of administration to patients for quick relief. They are a convenient form to dispense drugs with a large dose $[1,2]$.

Addition of effervescent granules into a glass of water just before the administration will be quickly dispersed or dissolved by the liberation of carbon dioxide in water due to an interaction between acid with alkali metal carbonates or bicarbonate. The dissolution of the drug in water,as well as taste masking, is enhanced due to liberation in carbon dioxide gas [3].

Carbamazepine is very slightly soluble in water [4], it is an antiepileptic drug, and it is also considered to be one of the most vital drugs for the relief of pain associated with trigeminal neuralgia, it shows erratic dissolution profile in gastric and intestinal fluid and its absorption is fairly complete after single oral doses due to its poor water solubility [5].

Cyclodextrins are capable of forming inclusion complexes with a wide variety of hydrophobic molecules by taking up a whole molecule, or some part of it, into the cavity. Thus it improves pharmaceutical properties like solubility, dissolution rate and stability. These complexes also act as penetration enhancers by increasing the availability of the drug at the surface of a biological membrane and even palatability without affecting their intrinsic lipophilicity or pharmacological properties [6].

The main aim of this work was to enhance patient compliance by the formulation of carbamazepine as unit dose effervescent granules to be easily taken by children and elderly patients. This requires improving the poor water solubility of carbamazepine, by preparing it as a soluble complex with $\beta$-cyclodextrin.

\section{MATERIALS AND METHODS}

Carbamazepine, $\beta$-cyclodextrin and croscarmellose sodium (Hyperchem, China), hydroxypropyl methyl cellulose (HPMC E5) and polyvinylpyrrolidone (PVP) (Himedica, India), citric acid (Panreac, Barcelona Espain), tartaric acid (Fischer, China), sodium bicarbonate (Furat Drug Industry, Iraq), mannitol (Sigma, Aldrich, Germany), aspartame (Gerhard, Buchmann KG, Germany) all other ingredients are of analytical grade.

\section{Methods}

Determination of carbamazepine saturated solubility in water

The solubility of carbamazepine was determined in water using the shake-flask method at $25{ }^{\circ} \mathrm{C}$. An excess amount of carbamazepine pure powder was taken and dissolved in water $(10 \mathrm{ml})$ with continuous shaking in the water bath (Copley scientific, U. K) for 48 $\mathrm{h}$ at $25^{\circ} \mathrm{C} \pm 2{ }^{\circ} \mathrm{C}$. Then sample was taken, filtered by using millipore filter paper $0.45 \mu \mathrm{m}$, and the filtrate was diluted suitably and analyzed spectrophotometrically (Specord, Japan spectrophotometer)at $284 \mathrm{~nm}$ to determine the dissolved quantity of carbamazepine [7]

\section{Preparation of carbamazepine- $\beta$-cyclodextrin complex}

Two steps were required to prepare carbamazepine- $\beta$-cyclodextrin complex:-

\section{First-phase solubility studies}

Phase solubility studies for both binary (carbamazepine and $\beta$ cyclodextrin) and ternary systems (carbamazepine, $\beta$-cyclodextrin and HPMC E5) were carried out according to the method reported by Higuchi and Connors [8] Excess amount of drug was added to 10 $\mathrm{ml}$ vials containing aqueous solutions of increasing concentrations of $\beta$-cyclodextrin $(0.001 \mathrm{M}$ to $0.01 \mathrm{M})$ and shaken at $25 \pm 0.5{ }^{\circ} \mathrm{C}$. 
Experiment for the ternary system was performed analogously to those for the binary systems, but in the presence of $0.25 \% \mathrm{w} / \mathrm{v}$ HPMC E5[9] After $48 \mathrm{~h}$ mixing, the samples were filtered through a millipore filter paper $0.45 \mu \mathrm{m}$., the concentration of the dissolved carbamazepine was determined spectrophotometrically at $284 \mathrm{~nm}$.

Phase solubility curve was obtained by plotting the molar concentration of the dissolved carbamazepine versus the molar concentration of $\beta$-cyclodextrin. The molar ratio of drug to $\beta$ cyclodextrin required for best complex formation and the degree of their association (Ka) is to be determined from the values of slopes and the intercepts (So) of the lines obtained from this curve. According to Equation [8].

$$
\mathrm{Ka}=\frac{\text { Slope }}{\text { So (1-Slope) }}
$$

Where so is the intrinsic solubility of the drug

\section{Second-solvent evaporation method for preparation of the complex}

For the preparation of carbamazepine- $\beta$-cyclodextrin complex, the aqueous solution of a required amount of $\beta$-cyclodextrin was added to a methanolic solution of carbamazepine. The resulting mixture was stirred for 1 hour and evaporated at a temperature of $45^{\circ} \mathrm{C}$ until dried. The dried mass was pulverized and sieved through sieve no.20 [10]

The ternary complex comprising of $0.25 \% \mathrm{w} / \mathrm{v}$ (HPMC E5) was prepared by first dissolving required amounts of $\beta$-cyclodextrin and polymer in distilled water which was then added to the methanolic solution of carbamazepine [9] and then the same procedure was done like that for the binary system.

\section{Physical mixture}

A quantity equivalent to 1 mole of carbamazepine and 1 mole of $\beta$ cyclodextrin were mixed in a mortar for about one hour with constant trituration, passed through sieve no. 20 and stored in a desiccator [11].

\section{Characterization of the complex}

\section{Solubility}

The solubility of the complexes was determined by shake flask method as mentioned previously. The results were compared with those of pure drug and physical mixture of drug and $\beta$-cyclodextrin.

\section{Percent practical yield}

Percentage practical yield was calculated to know about the efficiency of the method. Inclusion complex was collected and weighed to determine practical yield from the following equation [12]

$$
\text { Practical yield }(\%)=\frac{\text { Practical mass }}{\text { Theoretical mass }(\text { Drug }+\beta-\text { cyclodextrin })} \times 100
$$

\section{Determination of drug content}

Drug content was determined by taking $5 \mathrm{mg}$ of complex and transferred to $50 \mathrm{ml}$ volumetric flask and volume was made up to the mark with distilled water. From this $1 \mathrm{ml}$ was taken in $10 \mathrm{ml}$ volumetric flask and the volume was adjusted up to the mark with methanol. The absorbance of the solution was measured spectrophotometrically at $285 \mathrm{~nm}$ [13]

\section{Differential scanning calorimetry (DSC)}

The DSC curves were obtained in a Shimadzu, Japan DSC using aluminum pan with about $2 \mathrm{mg}$ of samples (pure drug, $\beta$-cyclodextrin, HPMC E5, physical mixture of drug and $\beta$-cyclodextrin, binary and ternary complexes), under dynamic $\mathrm{N} 2$ atmosphere and heating rate of $10{ }^{\circ} \mathrm{C}$ min- 1 under a temperature range $25^{\circ} \mathrm{C}-400{ }^{\circ} \mathrm{C}[14]$

\section{Preparation of granules by wet granulation}

For preparation of effervescent granules by wet granulation method; an amount of complex (binary or ternary) equivalent to $200 \mathrm{mg}$ or $100 \mathrm{mg}$ of carbamazepine was mixed with a certain quantity of effervescent base, Croscarmellose sodium as a superdisintegrant to promote the bursting effect of the granules [15], aspartame as sweetener and mannitol was added as a diluent to make 5 gram of powder as a sachet dosage form. Sufficient amount of $2 \%$ alcoholic solution of polyvinylpyrrolidone (PVP) as a binder was added to make a damp mass. This mass was passed through sieve no 20 to get granules which were dried in hot air oven at $40{ }^{\circ} \mathrm{C}$ [16]

Carbamazepine dispersible granules were prepared in the same way but without the presence of the effervescent base

\section{Evaluation of granules}

\section{In vitro effervescence time}

One dose of effervescent or dispersible granules ( 5 g.) equivalent to 200 or $100 \mathrm{mg}$ of carbamazepine was added in $200 \mathrm{ml}$ of distilled water and the time for in vitro effervescence till it ceased or that for complete disintegration of dispersible granules was determined [17]

\section{pH of solution}

One dose of (100 or 200$) \mathrm{mg}$ granules was added to $(200 \mathrm{ml})$ distilled water. After complete dissolution, the solution $\mathrm{pH}$ was measured by a pH meter (Hanna, Italy) [18]

\section{In vitro drug release}

One dose of the effervescent granules was accurately weighed and added to $200 \mathrm{ml}$ of distilled water in an appropriate beaker. After 5 min [4], filtration was done with a millipore filter paper $0.45 \mu \mathrm{m}$. The filtrate was diluted with water, and the quantity of the released carbamazepine was determined spectrophotometrically at $284 \mathrm{~nm}$

\section{Determination of flow properties}

The flow properties were determined only for those formulas which release an acceptable amount of drug to give us further conformation about ease of packaging of these granules by the manufacturer and the ease of handling by the patient.

The flow property can be determined by measuring the angle of repose, bulk and tapped density, Hausner's ratio and compressibility index [1]. The results were compared with the pure powder.

\section{Angle of repose}

The angle of repose is a relatively simple technique for estimating the flow properties of a powder. It can easily be determined by allowing powder to flow through a funnel, and fall freely onto a surface. The height and diameter of the resulting cone are measured and the angle of repose is calculated from this equation

$$
\text { Angle of repose } \emptyset=\tan ^{-1} \frac{\mathrm{h}}{\mathrm{r}}
$$

Where $\mathrm{h}$ is the height of the powder cone and $\mathrm{r}$ is the radius of the powder cone

\section{Bulk density}

It is the ratio of the total mass of powder to the bulk volume of powder. It was measured by pouring a weighted mass of powder into a measuring cylinder, and the initial volume was noted. This initial volume was called the bulk volume. The bulk density was calculated according to the equation mentioned below and it was expressed in $\mathrm{g} . / \mathrm{cm}^{3}$.

$$
\text { Bulk density }=\frac{\text { Weight of powder }}{\text { Bulk volume }}
$$

\section{Tapped density}

It is the ratio of total mass of the powder to the tapped volume of the powder. It was measured by pouring a weighted mass of powder into a measuring cylinder. Tapped volume was measured by tapping the powder until no further change in the powder volume was observed. Tapped density was expressed in $\mathrm{g}$./ $/ \mathrm{cm} 3$ and was given by this equation:

$$
\text { Tapped density }=\frac{\text { Weight of powder }}{\text { Tapped volume }}
$$

\section{Compressibility index (Carr's index)}

Compressibility is the ability of the powder to decrease in volume under pressure using bulk density and tapped density. The 
percentage compressibility of powder was determined, which was given as Carr's index (\%). It was indirectly related to the relative flow rate.

$$
\text { Carr's index }=\frac{\text { Tapped deensity }- \text { Bulk densiy }}{\text { Tapped density }} \times 100
$$

\section{Hausner's ratio}

Hausner's ratio was determined by the following equation

$$
\text { Hausner's ratio }=\frac{\text { Tapped density }}{\text { Bulk density }}
$$

Factors affecting the physical properties of effervescent granules

\section{Effect of effervescent components}

The effects of citric acid and tartaric acid on effervescence time and $\mathrm{pH}$ and amount of drug released were investigated by changing the ratio of citric acid: tartaric acid: sodium bicarbonate as follows: 1: 2: 3.4 (for F1 and F3) and doubling the amount of citric acid for (F2 and F4) keeping the total concentration of the effervescent base within the formula constant that is equal to $60 \% \mathrm{w} / \mathrm{w}$ as shown in table 1

\begin{tabular}{|c|c|c|c|c|}
\hline Ingredient (mg) & F1 & F2 & F3 & F4 \\
\hline Complex equivalent to $200 \mathrm{mg}$ carbamazepine & 1222 & 1222 & 1222 & 1222 \\
\hline Citric acid & 468.75 & 810.8 & 468.75 & 810.8 \\
\hline Tartaric acid & 937.5 & 810.8 & 937.5 & 810.8 \\
\hline Sodium bicarbonate & 1593.75 & 1378.4 & 1593.75 & 1378.4 \\
\hline Croscarmellose sodium & 150 & 150 & 75 & 75 \\
\hline PVP 2\%Alcoholic solution & Q. S & Q. S & Q.S & Q.S \\
\hline Aspartame & 5 & 5 & 5 & 5 \\
\hline Mannitol up to & 5000 & 5000 & 5000 & 5000 \\
\hline
\end{tabular}

Table 1: Composition of effervescent granules of carbamazepine/ $\beta$-cyclodextrin complex

\section{Effect of the concentration of effervescent base}

The effect of concentration of effervescent base on the physical properties of effervescent granules prepared from ternary complex was studied by using $36 \% \mathrm{w} / \mathrm{w}$ for $\mathrm{F} 5,48 \% \mathrm{w} / \mathrm{w}$ for $\mathrm{F} 6$, and $60 \% \mathrm{w} / \mathrm{w}$ for $\mathrm{F} 7$ and $\mathrm{F} 9$ keeping the ratio of citric acid: tartaric acid: sodium bicarbonate as 1: 2: 3.4. While F8 "and F10* represented dispersible granule free from the effervescent base. The compositions of all these formulas are shown in tables $2 \mathrm{~A}$ and 2B.

Table 2A: Composition of effervescent and dispersible granules of carbamazepine/ $\beta$-Cyclodextrin/HPMC E5 complex equivalent to 200 mg carbamazepine

\begin{tabular}{lllll}
\hline Ingredient (mg) & F5 & F6 & F7 & F8* \\
\hline Complex equivalent to 200 mg carbamazepine & 1372.3 & 1372.3 & 1372.3 & 1372.3 \\
Citric acid & 281.25 & 375 & 468.75 & 0 \\
Tartaric acid & 562.5 & 750 & 937.5 \\
Sodium bicarbonate & 956.25 & 1275 & 1593.75 & 0 \\
Croscarmellose sodium & 150 & 150 & 150 & 150 \\
PVP 2\% Alcoholic solution & Q. S. & Q. S. & Q. S. & Q. S. \\
Aspartame & 5 & 5 & 5 & 5 \\
Mannitol up to & 5000 & 5000 & 5000 & 5000 \\
\hline
\end{tabular}

F 8* Dispersible granules formula

Table 2B: Composition of effervescent and dispersible granules of carbamazepine/ $\beta$-cyclodextrin/HPMC E5 complex equivalent to 100

\begin{tabular}{|c|c|c|}
\hline Ingredients (mg) & F9 & F10" \\
\hline Complex equivalent to $100 \mathrm{mg}$ carbamazepine & 686.15 & 686.15 \\
\hline Citric acid & 468.75 & 0 \\
\hline Tartaric acid & 937.5 & 0 \\
\hline Sodium bicarbonate & 1593.75 & 0 \\
\hline Croscarmellose sodium & 150 & 150 \\
\hline PVP 2\% Alcoholic solution & Q.S. & Q.S. \\
\hline Aspartame & 5 & 5 \\
\hline Mannitol up to & 5000 & 5000 \\
\hline
\end{tabular}
mg carbamazepine

F 10 *Dispersible granules formula

\section{Effect of concentration of superdisintegrant}

To study the effect of concentration of superdisintegrant, F1and F2 which composed of $3 \% \mathrm{w} / \mathrm{w}$ croscarmellose sodium were prepared (table 1) and the physical properties of the resultant granules were compared with those in F3 and F4 which composed of $1.5 \%$ croscarmellose sodium

\section{Statistical analysis}

Using Microsoft Excel 2010, the results of the experiments are given as a mean sample (of three results) \pm standard deviation (SD).

\section{RESULTS AND DISCUSSION}

\section{Determination of saturated solubility in water}

The saturated solubility of carbamazepine in water was found to be equal to $173.3 \mathrm{mcg} / \mathrm{ml}$ or $173.3 \mathrm{mg} / \mathrm{l}$, which is nearly the same as the reported value $(170 \mathrm{mg} / \mathrm{l})$ This indicated that the drug is very slightly soluble in water [19]

\section{Preparation of carbamazepine complex}

\section{Phase solubility studies}

No changes in $\lambda$ max of the drug were found after complexation with $\beta$-cyclodextrin. Hence the concentration of the dissolved carbamazepine was determined spectrophotometrically at 284 $\mathrm{nm}$ which is the $\lambda$ max of the drug in water. The phase solubility curve (fig. 1) showed that there is a linear increase in the solubility of the drug with the increase in the molar concentration of $\beta$-cyclodextrin alone or in the presence of HPMC E5. The further increase in the solubility of the drug in the presence of HPMC E5 in comparison to that of $\beta$-cyclodextrin alone can be explained to be as a result of the synergistic effect between these components [20] 


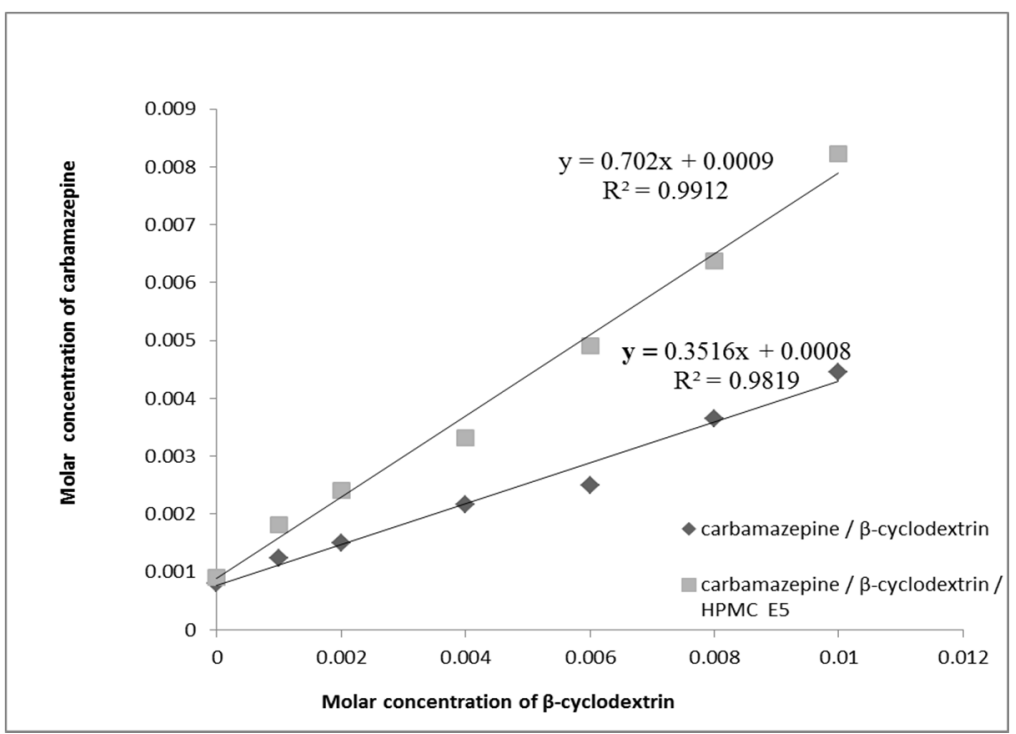

Fig. 1: Phase solubility study of carbamazepine/ $\beta$-cyclodextrin and carbamazepine/ $\beta$-cyclodextrin/HPMC E5 complexes

Since the slope of the lines in both cases was less than 1 , so the drug formed a complex with $\beta$-cyclodextrin in a molar ratio of 1:1[8]. Therefore, this ratio was used for the preparation of complexes. Also the association constant (Ka) for carbamazepine/ $\beta$-cyclodextrin was equal to $684.38 \mathrm{M}^{-1}$ while the (Ka) for carbamazepine/ $\beta$-cyclodextrin/HPMC E5 was equal to $2636.31 \mathrm{M}-1$ which indicate that HPMC E5 enhance complexation of carbamazepine in the ternary system [20]. Both values were within the accepted range value of the association constant is between 50 and $5000 \mathrm{M}^{-1}[21]$

\section{Characterization of the complex \\ Physical properties}

The physical properties of the prepared carbamazepine complexes in comparison with those of pure drug and the physical mixture of drug and $\beta$-cyclodextrin are summarized in table 3 . The results indicated that the solubility of the drug increased due to the presence of $\beta$-cyclodextrin (physical mixture) and formation of an inclusion complex with or without HPMC E5 which enhanced the wettability of particles, resulting in increased the solubility of the drug [20]

Table 3: The physical properties of the prepared carbamazepine complexes, pure drug and the physical mixture of drug and $\beta$ cyclodextrin

\begin{tabular}{|c|c|c|c|}
\hline Component & Solubility* & Percent Yield & Drug content \\
\hline Carbamazepine & $173.3 \mathrm{mcg} / \mathrm{ml} \pm 0.36$ & $-\cdots$ & ---- \\
\hline Physical mixture & $1.46 \mathrm{mg} / \mathrm{ml} \pm 0.035$ & $100 \%$ & $100 \%$ \\
\hline Carbamazepine/ $\beta$-cyclodextrin complex & $2.04 \mathrm{mg} / \mathrm{ml} \pm 0.106$ & $94.8 \%$ & $100 \%$ \\
\hline Carbamazepine/ $\beta$-cyclodextrin/HPMC E5 complex & $4.024 \mathrm{mg} / \mathrm{ml} \pm \pm 0.107$ & $93.2 \%$ & $100 \%$ \\
\hline
\end{tabular}

* Results are expressed as mean $\pm S D, n=3$

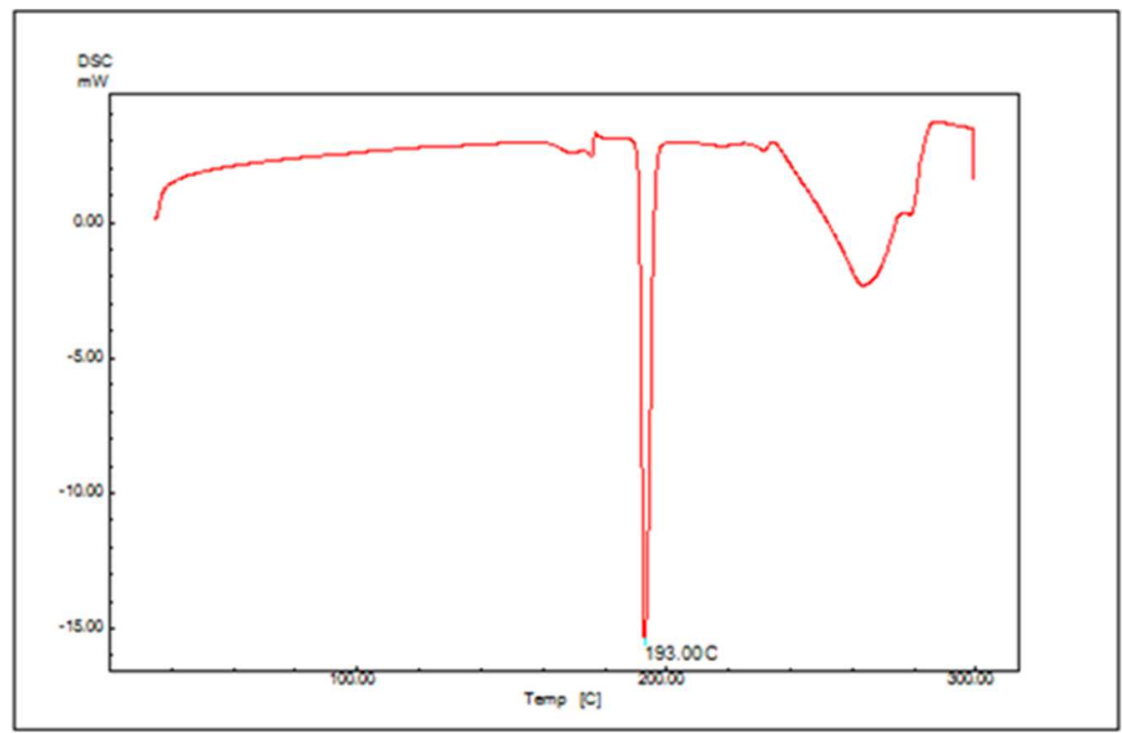

(A) 


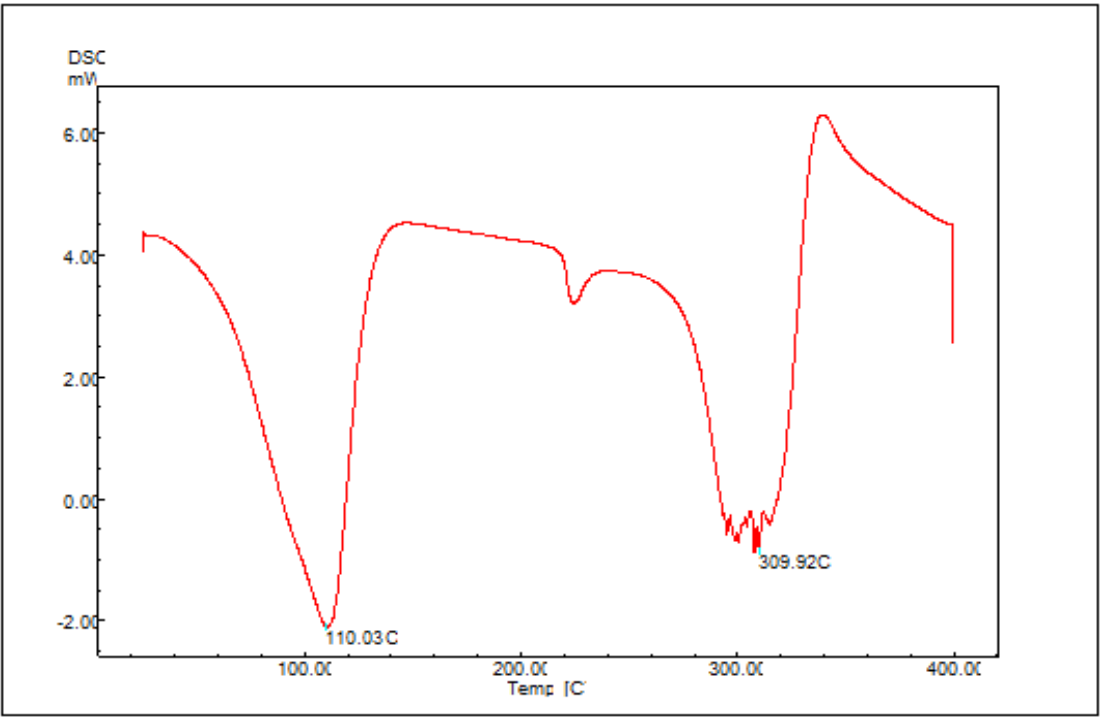

(B)

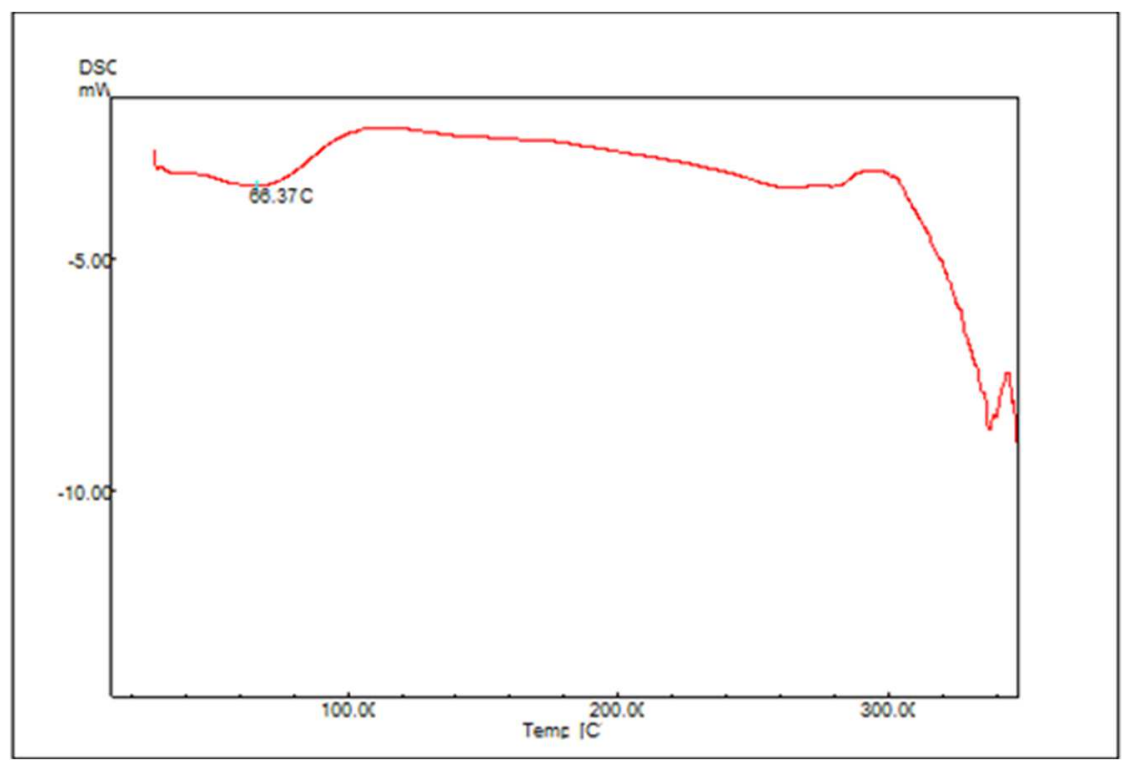

(C)

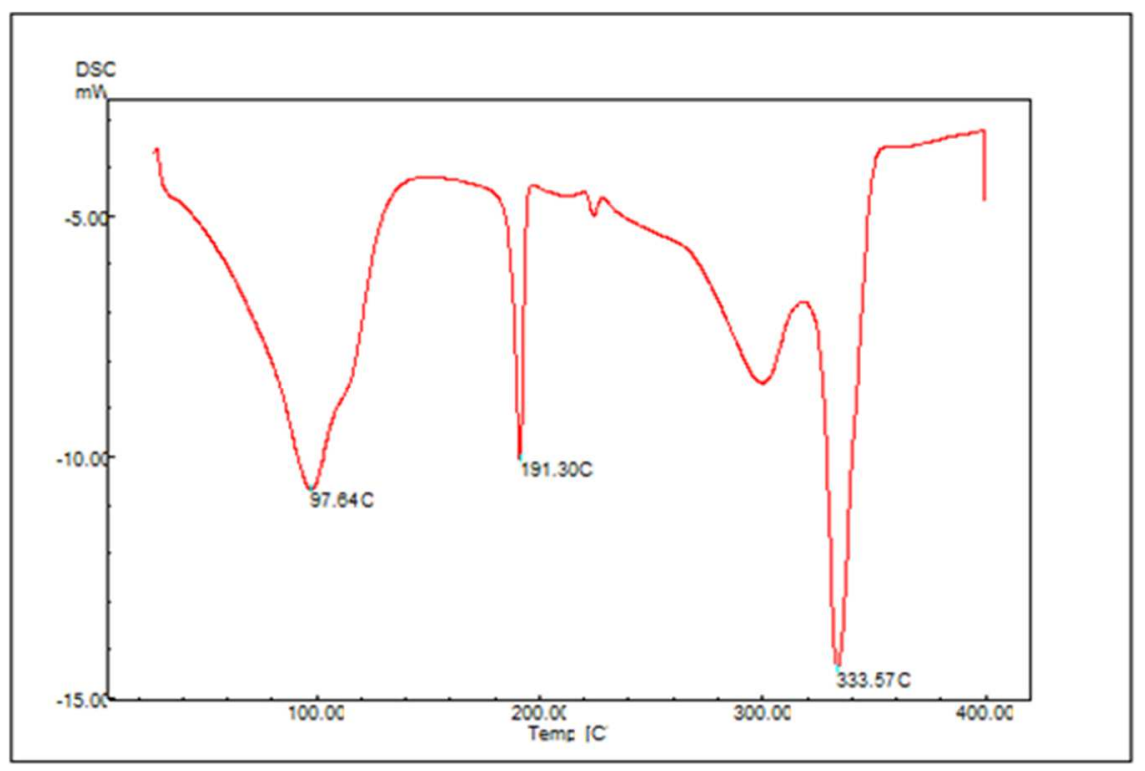

(D) 




(E)

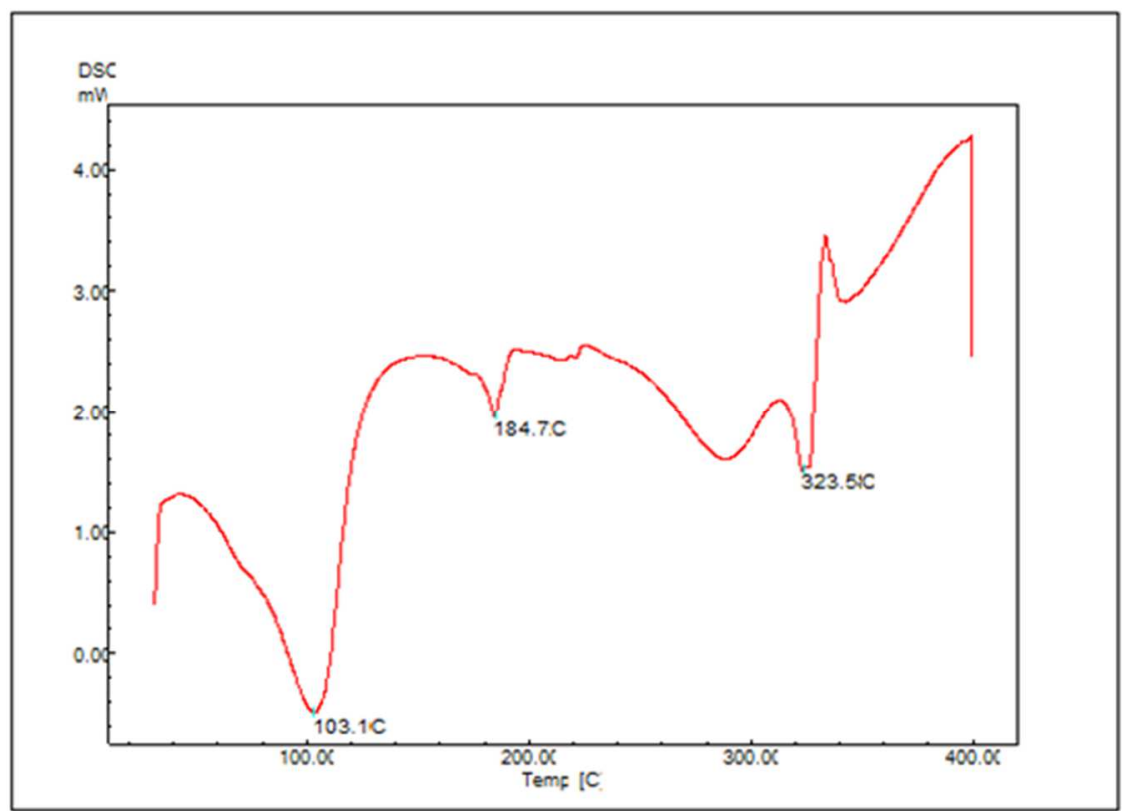

(F)

Fig. 2: DSC thermogram of (A) Carbamazepine, (B) $\beta$-Cyclodextrin, (C) HPMC E5, (D) Physical mixture, (E) $\beta$-cyclodextrin/Carbamazepine complex and (F) $\beta$-Cyclodextrin/Carbamazepine/HPMC E5 complex

\section{Differential scanning calorimetry (DSC)}

The DSC thermograms of carbamazepine, $\beta$-cyclodextrin, HPMC E5, physical mixture of carbamazepine/ $\beta$-cyclodextrin and carbamazepine/ $\beta$-cyclodextrin/HPMC E5 complex are illustrated in (fig. 2A-F). The pure drug showed a sharp endothermic peak at 193 ${ }^{\circ} \mathrm{C}$ corresponding to its melting point. Thermogram of the $\beta$ cyclodextrin showed a broad peak at $110.03{ }^{\circ} \mathrm{C}$ which is attributed to dehydration of water molecules present in $\beta$-cyclodextrin cavity while the peak at $309.92{ }^{\circ} \mathrm{C}$ corresponds to its melting point, while, HPMC E5 showed no sharp endothermic peaks indicting no exact melting points [20].

Physical mixture of system showed characteristic peaks for both the drug and the peaks $\beta$-cyclodextrin with slight decrease in their intensity due to dilution effect while, in carbamazepine/ $\beta$ cyclodextrin complex there was a small endothermic peak at 174.2
${ }^{\circ} \mathrm{C}$, which is attributed to the presence of a small amount of polymorphic form of carbamazepine [19] and a decrease in the intensity of the characteristic endothermic peak of carbamazepine at $188.41{ }^{\circ} \mathrm{C}$. In addition, the intensity of this peak was further decreased in carbamazepine/ $\beta$-cyclodextrin/HPMC E5 complex suggests that the complexation efficiency was enhanced due to the presence of this polymer leading to a decrease in the amount of free drug in the ternary complex as compared to physical mixture [20].

\section{Preparation of granules}

Factors affecting the physical properties of effervescent granules

\section{Effect of effervescent components}

Formulas F1 and F3 with a ratio of citric acid: tartaric acid: sodium bicarbonate of 1:2:3.4, showed different physical properties than F2 
and F4 with doubling the amount of citric acid although the ratio of the effervescent base within the formula remains constant. The drug released from F1and F3 was greater than that from F2 and F4 (table 4). The difference in the in vitro drug release can be explained to be due to the fact that the citric acid may displace the drug from $\beta$ cyclodextrin cavity which led to decrease in its solubility and hence it's amount in the effervescent solution $[22,23]$.
In addition, the results in table 4 showed that all formulas had an acceptable $\mathrm{pH}$ for pharmaceutical solutions for oral administration [24] and effervescent time [4], but they did not release an acceptable amount of the drug [25]. This indicates that complexation of the drug with $\beta$-cyclodextrin only was not sufficient to give the required solubility. Therefore, HPMC E5 was added to prepare ternary complex.

Table 4: Effect of effervescent components on physical properties of granules of carbamazepine/ $\beta$-cyclodextrin complex

\begin{tabular}{|c|c|c|c|c|}
\hline Parameter & F1 & F2 & F3 & F4 \\
\hline Amount of drug released $\%$ & $63 \% \pm 1.73$ & $55.8 \% \pm 0.782$ & $60 \% \pm 1.73$ & $47.2 \% \pm 0.173$ \\
\hline $\mathrm{pH}$ & $5.6 \pm 0$ & $5.1 \pm 0.1$ & $5.6 \pm 0$ & $5.0 \pm 0.1$ \\
\hline Effervescent time (second) & $150 \pm 0.013$ & $140 \pm 0.022$ & $160 \pm 0.01$ & $150 \pm 0.012$ \\
\hline
\end{tabular}

Results are expressed as mean $\pm \mathrm{SD}, \mathrm{n}=3$

\section{Effect of concentration of effervescent base}

This effect was studied utilizing F5, F6, F7, F8 with the effervescent base ratio of (1: 2: 3.4) in different percentage within the formula (36\%, $48 \%$ and $60 \%$ and $0 \%$, respectively).

Slightly higher amount of drug was released from effervescent granules (F5, F6, and F7) than dispersible granules (F8) as shown in table 5. This indicates that the effervescent base had a role in enhancing the solubility of the drug. This result was in agreement with that obtained by Om M. Bagade et al. [26]. Same results were obtained with an effervescent and dispersible granules (F9 and F10) containing $100 \mathrm{mg}$ drug (table 6).

\section{Effect of concentration of superdisintegrant}

Formulas F1 and F2 with a greater concentration of croscarmellose sodium (3\%) gave higher in vitro drug release than the corresponding formulas of less concentration F3 and F4 (1.5\%) as shown in table 4 . This was because the higher percentage of porous particle that enabled them to rapidly absorbed liquid into the formula by capillary action and generated rapid volume expansion and hydrostatic pressure that resulted in granular disintegration leading to increasing the in vitro drug release [16]. Therefore croscarmellose sodium in a concentration of $3 \%$ was used for the preparation of other formulas.

\section{Determination of flow properties of granules}

The flow properties for those formulas which release an acceptable amount of drug are shown in table 7. The values for angle of repose were found in the range of 12.09 to 14.3. Carr's (Compressibility) index of the prepared blends falls in the range of $9.19-12.87 \%$. The Hausner's ratio falls in the range of $1.10-1.147 \%$ which indicated excellent flow properties of all the prepared granules [1].

Table 5: Effect of concentration of effervescent base of effervescent and dispersible granules of carbamazepine/ $\beta$-cyclodextrin/HPMC E5 complex

\begin{tabular}{lllll}
\hline Parameter & F5 & F6 & F7 & F8 $^{*}$ \\
\hline Amount of drug released \% & $96.4 \% \pm 0.173$ & $97.4 \% \pm 0.173$ & $97.5 \% \pm 0.264$ & $95.6 \% \pm 0.264$ \\
pH & $5.6 \pm 0.1$ & $5.5 \pm 0.1$ & $5.6 \pm 0$ & $5.7 \pm 0.1$ \\
Effervescent time (second) & $130 \pm 0.021$ & $145 \pm 0.02$ & $175 \pm 0.01$ & No effervescence \\
\hline
\end{tabular}

Results are expressed as mean $\pm \mathrm{SD}, \mathrm{n}=3$

Table 6: Effect of concentration of effervescent base of effervescent and dispersible granules of carbamazepine/ $\beta$-cyclodextrin/HPMCE5 complex equivalent to $100 \mathrm{mg}$ carbamazepine

\begin{tabular}{lll}
\hline Parameter & F9 & F10* \\
\hline Amount of drug released \% & $97.4 \% \pm 0.173$ & $95.8 \% \pm 0.36$ \\
pH & $5.6 \pm 0.1$ & $5.7 \pm 0.1$ \\
Effervescent time (second) & $170 \pm 0.01$ & No effervescence \\
\hline
\end{tabular}

Results are expressed as mean \pm SD, $n=3$

Table 7: Evaluation of flow properties of granules

\begin{tabular}{|c|c|c|c|c|c|}
\hline Formulation & $\begin{array}{l}\text { Angle of } \\
\text { repose }\end{array}$ & $\begin{array}{l}\text { Bulk density } \\
\left(\mathrm{g} . / \mathrm{cm}^{3}\right)\end{array}$ & $\begin{array}{l}\text { Tapped density } \\
\left(\mathrm{g} . / \mathrm{cm}^{3}\right)\end{array}$ & $\begin{array}{l}\text { Compressibility index (Carr's) } \\
(\%)\end{array}$ & $\begin{array}{l}\text { Hausner's } \\
\text { ratio }\end{array}$ \\
\hline F5 & $14.3 \pm 0.265$ & $0.44 \pm 0.0 .02$ & $0.505 \pm 0.01$ & $12.87 \pm 0.05$ & $1.147 \pm 0.02$ \\
\hline F6 & $14.28 \pm 0.096$ & $0.448 \pm 0.01$ & $0.505 \pm 0.03$ & $11.28 \pm 0.03$ & $1.127 \pm 0.05$ \\
\hline F7 & $14.3 \pm 0.173$ & $0.465 \pm 0.02$ & $0.528 \pm 0.05$ & $11.93 \pm 0.03$ & $1.135 \pm 0.07$ \\
\hline F8 & $12.09 \pm 0.108$ & $0.430 \pm 0.02$ & $0.489 \pm 0.01$ & $12.06 \pm 0.03$ & $1.137 \pm 0.05$ \\
\hline F9 & $12.3 \pm 0.36$ & $0.458 \pm 0.01$ & $0.511 \pm 0.03$ & $10.37 \pm 0.03$ & $1.116 \pm 0.02$ \\
\hline F10 & $12.09 \pm 0.082$ & $0.435 \pm 0.02$ & $0.479 \pm 0.02$ & $9.19 \pm 0.01$ & $1.10 \pm 0.02$ \\
\hline
\end{tabular}

Results are expressed as mean $\pm \mathrm{SD}, \mathrm{n}=3$

\section{CONCLUSION}

Effervescent and dispersible granules of carbamazepine with good flow properties can be successfully prepared by complexation of the drug with $\beta$-cyclodextrin and HPMC E5 as ternary complex since this complex enhance its solubility. Effervescent granules with effervescent base of 1:2:3.4 (citric acid/tartaric acid and sodium bicarbonate), respectively in an amount not less than $48 \% \mathrm{w} / \mathrm{w}$ and 
$3 \% \mathrm{w} / \mathrm{w}$ croscarmellose sodium within the formula may be considered as a more appropriate formulas regarding the amount of drug released within $5 \mathrm{~min}$

\section{AUTHORS CONTRIBUTIONS}

All the author have contributed equally

\section{CONFLICT OF INTERESTS}

Declared none

\section{REFERENCES}

1. Aulton ME. Pharmaceutics: the science of dosage form design. $2^{\text {nd }}$ ed. New York: Churchill Livingstone; 2002.

2. Palanisamy P, Abhishekh R, Kumar KD. Formulation and evaluation of effervescent tablet of aceclofenac. Int Res J Pharm 2011;2:185-90

3. Cherukuri PC, Palanisamy P, Krishna VA, Aparna S, Ali S S, Rakesh $\mathrm{P}$, et al. Formulation and evaluation of effervescent tablets of paracetamol. Int J Pharm Res Dev 2011;3:76-104.

4. British Pharmacopoeia. Vol. III. Formulated preparations: General Monographs; 2009.

5. Rogawski MA, Loscher W, Rho JM. Mechanisms of action of antiseizure drugs and the ketogenic diet. Cold Spring Harb Perspect Med 2016;6:1-28.

6. Shahira F El-Menshawe, Essam E, Adel A Ali, Ahmed A Abderhman. Enhancement of lornoxicam solubility by inclusion complexation with cyclodextrin: preparation and characterization. Int J Pharm Pharm Sci 2017;9:132-8.

7. Jouyban A. Hand book of solubility data for pharmaceuticals. $1^{\text {st }}$ ed. Taylor and Francis Group USA; 2010.

8. Higuchi T, Connors KA. Phase solubility techniques. ADV Anal Chem Instrum 1965;4:117-212.

9. Jagdale SC, Gawali VU, 10-Kuchekar BS, Chabukswar AR. Formulation and in vitro evaluation of taste-masked orodispersible dosage form of diltiazem hydrochloride. Braz J Pharm Sci 2011;47:908-16.

10. Kuchekar BS, Narkhede M. The effect of water soluble polymers on felodipine aqueous solubility and complexing abilities with natural and modified $\beta$-cyclodextrin. Indian J Pharm Sci 2007;2:197-202.

11. Shirser P, Rao KS, Iqbal MM. Formulation and evaluation of cyclodextrin inclusion complex tablets of water insoluble drugglimepiride. Int J Res Pharm Chem 2012;2:222-30.

12. Shekhr I, Gupta V, Jain A, Gupta N. Preparation and characterization of $\beta$ cyclodextrin aspirin inclusion complex. Int J Pharm Life Sci 2011;2:704-10.
13. Parmar GR, Gandhi KS, Sailor GU, Chauhan SP, Seth AK. Influence of ethylcellulose on dissolution profile of carbamazepine cyclodextrin complex. Iran J Pharm Res 2014;6:43-7.

14. Doile MM, Fortunato KA, Schmücker IC, Schucko SK, Silva MAS, Patrik 0 Rodrigues. Physicochemical properties and dissolution studies of dexamethasone acetate- $\beta$-. cyclodextrin inclusion complexes produced by different methods. AAPS PharmSciTech 2008;9:314-21.

15. Ashok T, Veeravalli SK, Pavan KM, Roshitha B. Effect of effervescence in combination with superdisintegrants in the formulation of propranolol $\mathrm{HCl}$ oral disintegrating tablets. Asian J Pharm Clin Res 2017;10:227-34.

16. Bhattacharyya S, Swetha G. Formulation and evaluation of effervescent granules of fexofenadine hydrochloride. Pharma Innovation J 2014;3:1-8.

17. Shanbhag P PS, Bhalerao S. Development and evaluation of antipyretic pediatric formulation. Int J Pharm Tech Res 2009;1:1373-5.

18. Sagar TB, Yogesh SP, Swati RS, Satish NL. Formulation development and evaluation of effervescent tablet of alendronate sodium with vitamin D3. J Drug Delivery Ther 2013;3:65-74.

19. Pandey A, Rath B. Improved physicochemical characteristics of amorphous drug solid dispersions. Res J Pharm Biol Chem Sci 2012;3:844-9.

20. Ashok RP, Pradeep RV. Preparation and evaluation of taste masked famotidine formulation using drug/ $\beta$ cyclodextrin/polymer ternary complexation approach. AAPS PharmSciTech 2008;9:544-50.

21. Gabriel OKL, Fung Tan YT, Khiang Peh K. Enhancement of norfloxacin solubility via inclusion complexation with $\beta$ cyclodextrin and its derivative hydroxypropyl- $\beta$-cyclodextrin. Afr J Plant Sci 2016;11:536-46.

22. Stella VJ, Rao VM, Zannou EA, Zia V. Mechanisms of drug release from cyclodextrin complexes. Adv Drug Delivery Rev 1999;36:316.

23. Neito N, Sanchez SE, Amoza G, Espinar O. Competitive displacement of drugs from cyclodextrin inclusion complex by polypseudorotaxane formation with poloxamer: implications in drug solubilization and delivery. Eur J Pharm Biopharm 2012;80:585-95

24. Jones D. Pharmaceutics-dosage form and design $1^{\text {st }}$ ed. Pharmaceutical Press: London; 2008.

25. USP30 NF25 2007.

26. Om M Bagade, Priyanka P Kharat, Rohini R Pujari, VS Raskar, Amruta M Shete, Maduhri D Vanve. Design and statistical optimization of antacid analgesic effervescent tablets by using factorial design. Int J Pharm Pharm Sci 2014;6:453-9. 